\title{
LA HISTORIA DE LA GUERRA DEL PELOPONESO DE TUCÍDIDES: LA SINRAZÓN DE LA POLIS
}

Juan Carlos Rodríguez Universidad del País Vasco

\section{RESUMEN}

Atendiendo al texto y su ordenación narrativa, se pone de relieve el papel central que ocupa en la Historia de la guerra del Peloponeso de Tucídides la relación entre la afirmación de la polis como valor prioritario y el desencadenamiento y la desmesura destructiva del conflicto bélico. La concepción de Pericles del bien común de Atenas aparece fundada en una valoración cultural de la polis coartadora del buen juicio, incompatible con la moderación e instigadora de la guerra. Esta valoración compartida por sus sucesores es la que llevó a Atenas a la perdición.

Tucídides centra su narración histórica en la guerra que enfrenta, durante veintisiete años, a Atenas y Esparta, las dos ciudades hegemónicas del mundo griego en su momento de apogeo. Nos presenta este conflicto bélico, que dividió al mundo helénico en dos bandos, como «la mayor conmoción que haya afectado a los griegos». Él mismo como ateniense participó en esta guerra, que «alcanzó, por así decirlo, a casi toda la humanidad», y que se saldó con la derrota de su ciudad.

El interés de la Historia de la Guerra del Peloponeso no se limita al de ser fundadora de una manera de elaboración histórica, caracterizada por una ma- 
yor exigencia de rigor y veracidad en el relato de los hechos que la de Heródoto, considerado el «padre de la Historia». Aunque el objeto de la investigación de Tucídides se ciñe temática, temporal y espacialmente, a esta guerra que él vivió, el propósito que preside su narración histórica, más allá del de proporcionar un reportaje lo más fiel posible del conflicto, es el de ofrecer una enseñanza de alcance universal. Tucídides mismo expone esta pretensión, que podemos caracterizar de filosófica, como finalidad de su historia cuando escribe: «Tal vez la falta de elemento mítico en la narración de estos hechos restará encanto a mi obra ante un auditorio, pero si cuantos quieren tener un conocimiento exacto de los hechos del pasado y de los que en el futuro serán iguales

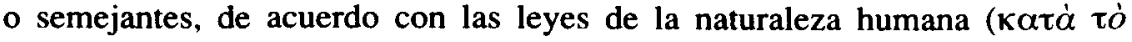

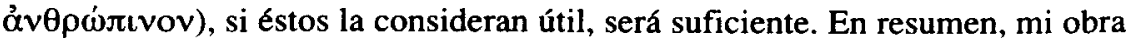

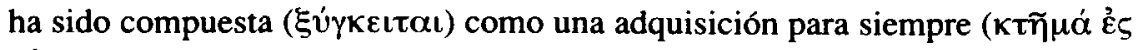

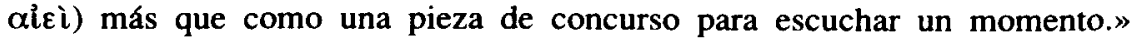
$(\mathrm{I}, 22,4)$

Tucídides persigue destacar lo universal en y a través del suceso particular que relata y del que enfatiza su importancia única. Por esta pretensión de descubrir lo universal y presentarlo como una adquisición para siempre, Tucídides es algo más que un historiador, y se le podría considerar un filósofo si no fuera por dos características capitales de su escritura que difícilmente encajan en los moldes de la elaboración filos6fica. Por una parte, lo distintivo de su proyecto no está sustentado en la abstracción de la argumentación conceptual, sino que se sirve de una encarnación narrativa concreta de la experiencia humana como único medio a través del cual explorar la naturaleza y los intereses humanos. Por otra, a diferencia de la clara y directa transmisión de conceptos y preceptos que caracteriza por lo general a la filosofía, la enseñanza principal que brinda la escritura de Tucídides es indirecta y se expresa en silencio a través de la urdimbre narrativa de su historia.

Como el autor mismo nos dice, su obra ha sido compuesta para lograr este objetivo de alcance universal que suponga una adquisición para siempre. La composición de la Historia de la Guerra del Peloponeso abarca dos planos: el de los hechos y el de los discursos. Los discursos y los debates nos presentan perspectivas distintas y enfrentadas desde las que considerar los hechos. Si, por una parte, este tipo de narrativa dificulta el discernimiento de la valoración propia del escritor ante los hechos narrados, pues sería un error identificar el pensamiento del autor con las opiniones o juicios que expresan los personajes de su historia, por otra parte, permite una comprensión más rica, menos unilateral o reduccionista que la del discurso unívoco, al ofrecernos la posibilidad de considerar los sucesos desde distintos punto de vista, y sacar a la luz aspectos de los mismos que, de otro modo, quedarían en la sombra. 
Aunque en algunas ocasiones, Tucídides hace juicios explícitos, en su propio nombre, la enseñanza más general de su obra se encuentra en su manera de organizar su narración. La reflexión más profunda del autor preside y condiciona la ordenación y estructuración narrativa de su historia. No sólo la prosa de Tucídides, que como afirma Nietzsche «creía dar dureza a sus ideas reduciéndolas por ebullición", es una prosa muy pensada y elaborada, sino que también la composición y articulación del conjunto de su discurso histórico es fruto maduro de una manifiesta premeditación. ${ }^{1}$

Los actores y oradores de la Historia son intérpretes, construyen sus narraciones y expresan sus juicios acerca de sus acciones, pero a su vez el historiador interpreta esta realidad desde un nivel superior. La narrativa de Tucídides, que engloba en un todo discursos y acciones, con sus consecuencias, pone de relieve la importancia de la comprensión de las situaciones históricas concretas. Lejos de definir la naturaleza humana de un modo estático y esencialista, el historiador la considera movida por una constante interacción de razón y deseo, que tiende a ser afectada de modo regular ante situaciones similares. ${ }^{2} \mathrm{De}$ este modo, la narrativa histórica de Tucídides, interpretación de la realidad ya interpretada por los agentes históricos, capacita al lector para el desarrollo del juicio y el autocontrol, pues «nos muestra que ciertos elementos de nuestra experiencia pueden muy bien implicar otros que aún no hemos experimentado o reconocido, $\mathrm{e}$ indica dónde deberíamos buscar consideraciones relevantes evaluando la realidad particular en la que participamos». En esta aportación de la obra de Tucídides in-

1 Tucídides empieza su historia presentándose como el que synégrapse tòn pólemon de los peloponesios y los atenienses. El verbo syggrápho significa "componer un testimonio escrito de, acentuando el componer junto al mero testimoniar», como advierte Carlos García Gual, quien señala que: «Es muy interesante subrayar que Tucídides no emplea el término de historia, sino que para referirse a su obra utiliza el de syggraphé Syggrapheús es el escriba que da fe de un determinado acto, sea jurídico o histórico. Pero junto al hecho de escribir, grápho, está también el de seleccionar y juntar determinados hechos en una composición, cuyo sentido depende de esa misma estructura de composición y selección previa. El prefijo griego syn alude a esa trabazón de lo histórico, que no está tanto en la realidad como en la misma concepción crítica y en la visión personal del autor del relato histórico». CARLOS GARCía GUAL, «La narrativa histórica griega», en La(s) Otra(s) Historia(s), n. ${ }^{\circ}$ 3, UNED, Bergara, 1991, p. 12.

2 En el análisis de la guerra civil en Corcira, Tucídides, refiriéndose a las luchas y calamidades escribe «que ocurren y siempre ocurrirán mientras la naturaleza humana sea la misma» $(I I I, 82,2)$ y observa que socavan el juicio del hombre y refuerza sus pasiones, pero a la vez no le da a esta tendencia general el carácter necesario y uniforme de una ley que alcanza a todos (cf. el tळ̃v $\pi 0 \lambda \lambda \tilde{\omega} v$ de III,82,2), y que se manifiesta siempre del mismo modo, pues sus consecuencias «son más violentas o más benignas, y diferentes en sus manifestaciones, según las variaciones de las circunstancias que se presentan en cada caso» (III,82,2). 
siste recientemente Cynthia Farrar ${ }^{3}$, dentro de una línea interpretativa que nos presenta la relación entre la razón y las pasiones, la oposición entre el juicio y lo irracional, como el hilo conductor y estructurador de la Historia de la Guerra del Peloponeso.

La analítica y reflexiva Historia de Tucídides muestra la necesidad de que la razón controle en determinadas situaciones las pasiones, del tipo de la ambición o la avidez (philotimía, pleonexía), si se quiere evitar verse envuelto en un desastre. En este sentido Tucídides analiza los caústicos efectos de la tiranía ateniense y pone al descubierto el modo y las causas que llevaron a esta situación, a la vez que sugiere que no era inevitable. En este sentido, C. FARRAR afirma con insistencia y de modo conclusivo que: «El nivel en el que el autocontrol era posible y en el que se podía, quizás, parar la desintegración del poder helénico, es el nivel de la comunidad política, de la polis.» ${ }^{4}$

C. FARRAR subraya 'la prioridad de la polis' como una de las enseñanzas principales de Tucídides. En este sentido escribe: «Dentro de la polis, el interés público tiene prioridad sobre los intereses privados», y en un mundo polarizado «no puede expresar durante más tiempo el deseo de al menos algunos de sus ciudadanos de adquirir más (pleonektein) o asegurar lo suyo a expensas del bien colectivo, sino que tiene que controlar este deseo, y por consiguiente a estos ciudadanos, en el interés del bienestar del grupo. Tucídides enfatiza la importancia del liderazgo, dirigido no hacia afuera, a la preservación del poder, sino hacia dentro, al control del deseo de actuar y expandirse. El líder actúa como mediador entre los ciudadanos y la entidad que ellos colectivamente constituyen, haciendo posible la unidad reflexiva. Cuando el espartano rey Arquidamos devastó el distrito de Acarnas, a la vista de los atenienses dentro de las murallas, la perspectiva de conflicto (stasis) en el juicio (gnome) de los atenienses necesitaba el ejercicio de la gnome de Pericles para preservar una política unificada». 5

Este pasaje, junto con la afirmación de la prioridad de la polis, recoge los puntos centrales de una interpretación de la Historia de la Guerra del Peloponeso, defendida por importantes estudiosos de esta obra, y que goza de gran predicamento. Nos referimos a las siguientes tesis:

3 "Thucydides: reflecting history-man and the community", cap. 5 de su libro The Origins of Democratic Thinking. The invention of politics in classical Athens, Cambridge Univ. Press, 1988.

${ }^{4}$ Op. cit. pp. 153 y ss.

s lbid. p. 156. 


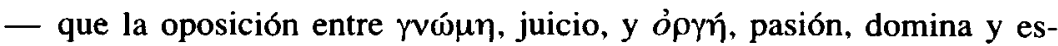
tructura la historia del imperialismo ateniense relatada por Tucídides ${ }^{6}$;

- que es la victoria de la pasión sobre el juicio lo que lleva a Atenas a su perdición;

- que este abandono del juicio, y de la prioridad del bien de la polis, es lo contrario de la conducta de Pericles, encarnación paradigmática del buen juicio, y caracteriza más bien a sus sucesores ${ }^{7}$.

Estas interpretaciones coinciden en presentar a Pericles como un hombre superior y excepcional, cuya condición de paradigma de predominio del juicio sobre la pasión, del bien de la polis sobre el bien particular, hacía inconcebible bajo su gobierno la expedición de conquista de Sicilia, que emprendieron sus sucesores, y el consiguiente resultado desastroso que llevó a Atenas a la derrota. «Pericles es la gnome de Atenas», declara C. FARRAR, quien interpreta que: «El contraste que Tucídides dibuja entre Pericles y sus sucesores, y entre la Atenas pericleana y la Atenas posterior a Pericles, enfatiza el carácter único y la significación normativa del liderazgo pericleano. Los políticos que dirigen Atenas después de la muerte de Pericles no estaban equipados para promover el bien conjunto de la polis: les faltaba gnome.» ${ }^{8}$

Estos análisis, a la vez que han puesto de relieve aspectos importantes de la obra de Tucídides, han ocultado otros que tienen que ver directamente con los valores culturales de la polis promotores de la guerra, asumidos y predicados como indiscutibles por el propio $\mathrm{Pe}$ ricles, y cuyos desastrosos efectos y costes constituyen una enseñanza capital de la Historia de la guerra del Peloponeso.

En lo que sigue defenderé una interpretación que el propio texto de Tucídides no sólo tolera sino que favorece, y que contradice esta valoración de la polis ateniense como entidad y valor prioritario ${ }^{9}$. La

- Farrar, C., en una nota, nos remite a toda una serie de estudiosos que consideran que esta interacción estructura la Historia. Ibid. p. 156. Señala también que en la Historia de Tucídides el término gnome ( $\gamma v \omega ́ \mu \eta$ ) designa «a la vez, la capacidad de valorar la realidad y lo que refrena las tendencias supersticiosas e impulsivas del hombre», y se aplica a cuestiones prácticas más que a teóricas, pp. 156-57.

7 Cf. DE Romilly, JACQueline., editora y traductora del texto de Tucídides («Les Belles Lettres», París 1953-1967), Thucydide et l'impérialisme athénien, Les Belles Lettres, París, 1951, pp. 276-279, que en esta interpretación muestra su acuerdo con ZAHN, R., Die erste Periklesrede (Thukydides 1, 140-44) (Leipzig, 1934).

${ }^{8}$ Farrar, C., op. cit., p. 165.

9 Me ha sido muy provechosa para el presente enfoque la lectura de Leo Strauss, La cité et l' homme, Agora, Paris 1987, p. 246 (traduc. francesa de The City and Man. University Press of 
concepción que Pericles defiende del bien común de Atenas está fundada en una valoración cultural de la polis coartadora del buen juicio, incompatible con la moderación e instigadora de la guerra. Esta valoración del estadista es compartida por sus sucesores y es la misma que justifica la expedición de conquista de Sicilia que causó la perdición de Atenas.

Para apoyar esta interpretación me centraré especialmente en los dos primeros libros de la Historia de la guerra del Peloponeso, por ser en éstos en los que está presente la figura destacada de Pericles y donde se expresa de modo más claro la imagen que los atenienses se hacen de su ciudad.

El libro primero no trata de la guerra propiamente dicha entre peloponesios y atenienses sino que se centra en sus causas. La cuestión legal o de derecho de saber cuál de las dos ciudades ha roto el tratado de paz vigente, no es el problema central, para Tucídides, en las relaciones entre Atenas y Esparta. Lo crucial, lo que motivó realmente la guerra entre peloponesios y atenienses, fue el miedo de Esparta al floreciente poderío de Atenas. Tucídides no deja lugar a dudas a este respecto, $y$ afirma explícitamente que «la causa más verdadera

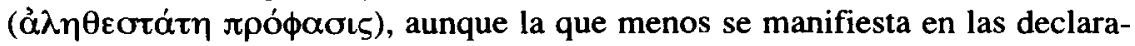
ciones, pienso que la constituye el hecho de que los atenienses al hacerse poderosos e inspirar miedo a los lacedemonios les obligaron a luchar». $(1,23,6$; también I.88,1).

La política de Atenas aparece representada como proyección de una voluntad de poder que provoca la polarización del mundo helénico. ${ }^{10}$

Los atenienses que se encontraban de negocios en Esparta, cuando los corintios habían convocado a los aliados en esta ciudad para incitarles a la guerra contra Atenas, justifican en su discurso (I.73-80) su imperio, tras aludir a que no lo habían conseguido por la fuerza sino por la dejación de los lacedemonios en su lucha contra los medos, declarando: «nosotros no hemos hecho nada ex-

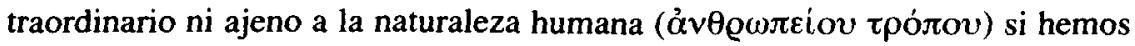
aceptado un imperio que se nos ha entregado y no hemos renunciado a él,

\footnotetext{
Virginia, 1964) cuyo capítulo titulado «Sur la Guerre des Péloponnésiens et des Athéniens de Thucydide" nos ofrece una profunda reflexión, en más de ciento veinte páginas, sobre el texto tucidideano. Llama la atención la ausencia completa de referencia a este trabajo entre los estudiosos y traductores de la obra de Tucídides, para los cuales parece ser inexistente.

${ }^{10}$ Los atenienses, incluido Pericles no reconocen que están fomentando la polarización. Más bien, al contrario, argumentan en distintas ocasiones que el ejercicio de la dominación, del imperio, y el mantenimiento de la seguridad son la misma cosa. (Pericles en II.62,3 y 63,2; tb. Alcibiades VI, 18,3).
} 
sometiéndonos a los tres motivos más poderosos: el honor, el temor y el inte-

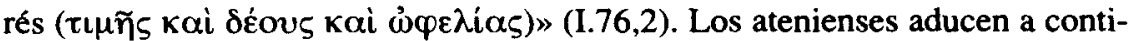
nuación «que siempre ha prevalecido la ley de que el más débil sea oprimido

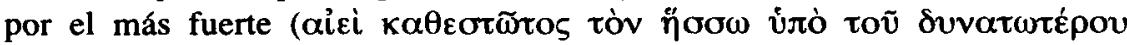
$\kappa \alpha \tau \varepsilon i \rho \gamma \varepsilon \sigma \theta \alpha \imath)$ ", y rechazan las razones de justicia porque son «razones que nunca ha puesto por delante nadie que pudiera conseguir algo por la fuerza para dejar de acrecentar sus posesiones. $Y$ son dignos de elogio quienes, aun

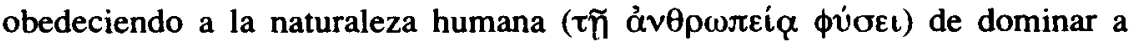

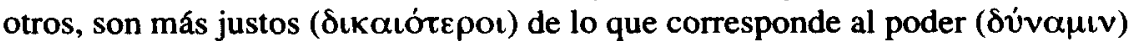
que está en sus manos» (I.76, 2-4). En su justificación del imperio ante un público hostil, los atenienses alegan su moderación, su subordinación a los acuerdos con los aliados, y su respeto a las leyes comunes en los pleitos de Atenas (I.77, 1).

Pero la justificación última del imperialismo ateniense, y el motor que lo impulsa, no es tanto una necesidad basada en la «ley del más fuerte» (que como vemos en este discurso puede contrarrestarse), el temor o el provecho, sino la gloria de la ciudad. El valor principal, el 'bien común' que la ideología de la ciudad de Atenas pone en juego, tanto para mostrar como necesario el desencadenamiento de la guerra como su mantenimiento, es la gloria que supone el ser la primera potencia, un imperio soberano y sin límites. Esto aparece tanto en el primer discurso de los atenienses en Esparta, como en los discursos de Pericles a sus conciudadanos, especialmente en los dos últimos.

La «ley de la fuerza», reconocida como natural por los atenienses, no constituye el núcleo de la ideología propia del imperialismo ateniense. Este «derecho natural del más fuerte» se presenta como una doctrina universal que caracteriza, por ejemplo, tanto a Esparta como a Atenas, y que en las dos únicas ocasiones en que es reivindicado por esta última lo es ante un público no ateniense (ante los espartanos y ante los melios). Por otra parte, esta «ley del más fuerte» no conduce indefectiblemente al expansionismo, tanto por el hecho de que puede ser domeñada por valores culturales, como en el primer discurso de los atenienses se manifiesta, como por el reconocimiento de la evidencia de que hay límites más allá de los cuales la expansión no está exenta de peligros.

Es preciso distinguir entre el derecho del fuerte a ejercer su dominio sobre el débil y la tendencia ilimitada a la expansión y a la conquista, incluso arrastrando serios peligros y enfrentándose a fuerzas no tan claramente débiles ". Esta segunda tendencia es la que nutre y pone en movimiento la idea de

"Ya en la transformación de la hegemonía ateniense en imperio, que relata Tucídides en la 'Pentecontecia', se da cuenta de la expedición de los atenienses a Egipto, en donde no eran superiores sino que afrontaron «una guerra de muy diversa suerte» que se saldó con su derrota (I.109, 1 ss.). 
honor y gloria eterna de la polis, que Atenas reivindica como única merecedora y presenta como su valor supremo.

Los dos discursos que Pericles dirige a los atenienses en el libro II son una ilustración indiscutible de la prioridad de este valor cultural que se presenta como «bien común". En ninguno de los dos discursos se menciona 'la ley natural del más fuerte', sino que la necesidad de aumentar los dominios, de «tener más» de un modo ilimitado (pleonexía), aparece indisolublemente ligada ${ }^{12}$ al ideal de gloria que es la aspiración y razón de ser de Atenas.

La gloria de la ciudad aparece subrayada, con claridad y contundencia, como motor de la conducta imperialista de Atenas en el discurso fúnebre de Pericles por los atenienses muertos el primer año de la guerra (II.35-46). Este gobernante se dirige a sus conciudadanos subrayando que la gloria actual de Atenas se queda corta en relación a las posibilidades de la ciudad, cuando declara: «entre las ciudades actuales, la nuestra es la única que, puesta a prueba, se muestra superior a su fama (ảKoñ $\varsigma \rho \varepsilon i \sigma o \omega v) »(I I .41,3)$. Para conseguir la gloria que merece y la admiración de generaciones futuras, dice Pericles a los atenienses, «nos bastará con haber obligado a todo el mar y a toda la tierra a ser accesibles a nuestra audacia, y con haber dejado por todas partes monu-

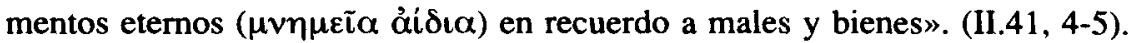
Por tal ciudad es natural (zíkós) sufrir y es más hermoso morir (II.42,3; 43,2). A cambio se recibe el «elogio que no envejece» ( y la gloria eterna ( $\dot{\eta} \delta o ́ \xi \alpha . . \alpha i \varepsilon i ́ u v \eta \sigma \tau o \varsigma) ~(44.2-3 ; 44.4)$.

En su último discurso, tras la peste y el saqueo de las tierras del Atica por los peloponesios, Pericles describe su consistente dedicación al punto de vista público, se define como «patriota ( 65,8 ). Reconoce el valor del buen juicio ( $\gamma$ vóv५) y los poderes de la expresión y de la persuasión, pero afirma que «quien tiene ambas capacidades, pero no

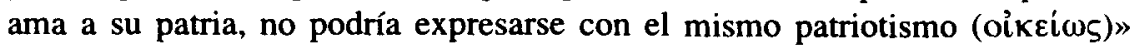
(II.60,6). Pericles aboga por la devoción a la polis como un todo, pero el bien común de ésta, que erige en valor primordial, es el mantenimiento de la superioridad y de la dominación ( $\pi \varepsilon \rho \iota \gamma \varepsilon v \varepsilon ́ \sigma \theta \alpha$ ). Para este estadista la dominación ateniense y el honor ligado a ella suministran el motivo para hacer la guerra (II.63,2; 64.3 ss.).

Ya en su primer discurso, en el que proclamaba que «es preciso saber, sin

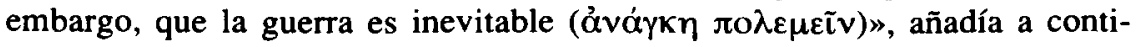
nuación "y que de los mayores peligros, tanto para una ciudad como para un particular, resultan los mayores honores ( $\mu \dot{\varepsilon} \gamma \iota \sigma \tau \alpha \iota \tau \iota \mu \alpha i) »(\mathrm{I} .144,3)$. Ahora, 
en este último discurso, reitera la idea cuando declara que «al habitar una gran ciudad y haber sido educados en costumbres dignas de ella, es preciso estar dispuesto a soportar las mayores desgracias para no oscurecer la reputación

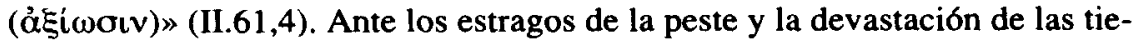
rras áticas que sufren los atenienses, a lo que Pericles recurre, en éste último discurso, como incentivo principal de la guerra, no es a los valores democráticos atenienses, sino a la grandeza ( $\mu \varepsilon \gamma \varepsilon \dot{\theta} \theta 0{ }_{5}$ ) del imperio ateniense. Invoca la grandeza honorífica de su imperio haciendo referencia explícita a su plasmación en extensión geográfica, e incita a los atenienses a aumentarla: «Vosotros creeis sin duda que vuestro imperio se extiende sólo sobre los aliados, pero yo declaro que de las dos partes del mundo abiertas al uso del hombre, la

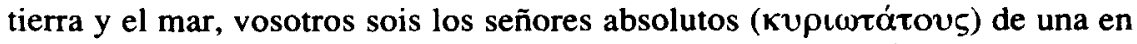
toda la extensión que ahora controláis, y en mayor medida ( lo proponéis.» (II.62,2). Conviene llamar la atención sobre esta última frase por lo que encierra de explícito llamamiento a la expansión, al «tener más» (epi pléon).

La gloria es el bien común por antonomasia, el valor supremo de la ciudad, el incentivo mayor de la guerra. Este honor, esta gloria, le viene a Atenas de su potencia (dynamis). «Y es natural que vosotros defendáis el honor de la ciudad, honor que le viene de un imperio, del que todos os enorgullecéis $»^{13}$, les recuerda Pericles a sus conciudadanos. Y esta potencia, para ser reconocida, se debe de materializar en una dominación creciente, en un «obtener más» sin fin. Así la inmortalidad que a la ciudad le procura la gloria está en relación directa con la expansión y la guerra. Pericles, en su alegato para la prosecución de la guerra, en una situación de grave asolación, vincula a los enfrentamientos bélicos el «mayor renombre» (ỏvo $\mu \alpha \mu \dot{\varepsilon} \gamma(\sigma \tau o v)$ del que goza Atenas, y recalca: «que ella posee la mayor potencia ( $\delta \dot{v} \alpha \mu(v)$ conseguida hasta nuestros días, cuya memoria $(\mu v \eta \dot{\mu} \mu \eta$ ), aunque ahora llegáramos a ceder un poco (pues todo ha nacido para disminuir), perdurará para siempre (és aỉocov) en las generaciones futuras; se recordará que somos los griegos que hemos ejercido nuestro dominio sobre mayor número de griegos, que hemos sostenido las mayores guerras tanto contra coaliciones como contra ciudades separadas, y que hemos habitado la ciudad más rica en toda clase de recursos y la más grande» (II.64, 3-4). Pericles reconoce que el dominar a otros conlleva el ser odiado, pero, añade, «el odio no dura mucho tiempo, mientras que el esplendor ( $\lambda \alpha \mu \pi \rho o ́ \tau \eta \varsigma)$ del presente y la gloria que se proyecta hacia el futuro ( $\delta \dot{o} \xi \alpha$

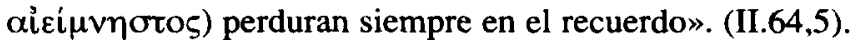

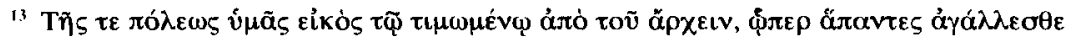
(II.63,1). 
Ahora bien, para que la gloria de la ciudad funcione realmente como incentivo de la guerra, para que los ciudadanos asuman este objetivo como su valor más preciado, subordinando y sacrificando a él sus tierras, sus bienes y sus vidas, es preciso que se identifique plenamente la vida del ciudadano a la de la ciudad como entidad, como abstracción, como ideal. Esta identificación es predicada, contundente y reiteradamente, por Pericles en sus discursos y es promovida por el ritual funerario que se repetía «durante toda la guerra, cada vez que se present 6 el caso» (II.34,7).

En los funerales que los atenienses celebraron en honor de los muertos en el primer año de guerra, y que terminan con el discurso fúnebre de Pericles, se manifiesta ya esta operación ideológica de anulación del individuo en aras de la idea de ciudad. Tucídides se detiene en explicarnos los actos rituales funerarios previos al discurso ${ }^{14}$.

La ceremonia y, sobre todo, la oración fúnebre desempeñan un papel central en la constitución de la ideología de la ciudad de Atenas. Ideología de la ciudad «en el sentido en el que es la 'ciudad' la que da su extrema coherencia a este discurso y le permite resistir a las diferencias y a las tensiones que lo 'real' podría introducir ahí», pero también ideología de la democracia «porque el igualitarismo transparente a sí mismo no existe más que en la muerte y reclamándose de la arete», como bien advierte NICOLE LOREAUX ${ }^{15}$.

14 «La ceremonia se desarrollaba del modo siguiente: tres días antes instalaban una tienda en la que exponen los huesos de los difuntos, y cada persona lleva al suyo la ofrenda que quiere. Cuando tiene lugar la conducción, unos carros transportan féretros de ciprés, uno por cada tribu; los huesos están en el féretro de la tribu a la que cada uno pertenecía. Sigue luego una litera vacia, con su cortejo fúnebre, en honor de los desaparecidos que no han podido ser hallados al levantar los cadáveres para el sepelio. Todos los que lo desean, tanto ciudadanos como extranjeros, pueden participar en el cortejo, y las mujeres de la familia están presentes en el entierro profiriendo sus lamentaciones. Los depositan luego en el sepulcro público, que está situado en el más bello arrabal de la ciudad, y en el que siempre han enterrado a los que han muerto en la guerra, excepción hecha de los de Maratón; a aquellos en atención a su valor excepcional, les dieron sepultura en el mismo lugar de la batalla. Y cuando los han cubierto de tierra, un orador designado por la ciudad, que sea considerado hombre de no escasa inteligencia y que sobresalga por su reputación, pronuncia en su honor un elogío adecuado; y después de esto, se retiran.» (II.34, 1-8).

19 LORAUX, NiCOLE, «Mourir devant Troie, tomber pour Athènes: de la glorie du héros a l'idée de la citè, en GNOLI, G., y VERNANT, J.P. (eds.) La mort, les morts dans les sociétés anciennes. Cambridge University Press \& Editions de la Maison des Sciences de l'Homme, París, 1982, p. 39. En lo que atañe al proceso por el que los funerales llevan a cabo esta ideologla de la ciudad seguimos a esta autora en los puntos centrales de este trabajo y del capítulo «La 'belle mort' ou

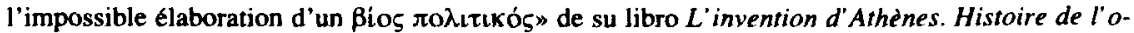
raison funébre dans la <citè classique>, Mouton éditeur. Paris. La Haye. New York. Éditions de l'Ecole des Hautes Études en Sciences Sociales. París 1981. 
En oposición a los funerales épicos, en los que sólo la élite de los héroes recibía los honores de un ritual funerario con exposición del cuerpo ( $p r o ́ t h e s i s$ ), banquete, concursos, y celebración de sus hazañas (kléa andrôn), la práctica funeraria democrática ateniense concede los mismos honores a todos los ciudadanos muertos en la guerra.

El esplendor con que la polis de Atenas celebra los funerales de los ciudadanos muertos en la guerra no tiene igual en las otras ciudades griegas. En Atenas los funerales son fundamentalmente colectivos e igualitarios. Los muertos sólo reciben individualmente las ofrendas de sus familiares en el tiempo de la exposición del cuerpo (próthesis), previo a la colectivización de los huesos. Aunque cada uno de los ciudadanos tiene derecho al recuerdo eterno mediante la inscripción de su nombre en el monumento, este nombre se registra sin patronímico ni demótico, que indique su pertenencia a una familia o a un espacio de vida, y se coloca en una lista, junto a los nombres de todos los demás muertos del año ordenados según la distribución cívica de las diez tribus clistenianas. Los huesos de los muertos se juntan en el féretro de la tribu clisteniana a la que cada uno pertenecía y la conducción tiene lugar en carros distribuidos del mismo modo (II.34,3) «Los depositan luego en el sepulcro púclico ( N. LORAUX, abstracto y político.

Los funerales cívicos, en su igualitarismo democrático, extienden a todos los ciudadanos lo que la aristocracia reservaba a una élite de héroes: la próthesis, la conducción (ekphorá) con carros, el depósito de los huesos en los ataúdes de madera de ciprés (incorruptible y símbolo de inmortalidad) y, sobre todo, el elogio.

El epitaphios lógos, que sirve de broche de oro a los funerales, no celebra ninguna gloria individual; en él todos los muertos son anónimos y homoioi. Sin embargo, el igualitarismo democrático ha asimilado, mediante una trasposición, los valores aristocráticos de la gloria. La 'fama inmortal' ( $\delta$ ó $\alpha \alpha$ á $\theta \dot{v} \alpha-$ to5) que de este modo colectivo celebran en prosa los oradores cívicos parece

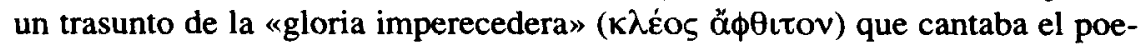
ta épico y otorgaba inmortalidad al héroe. Pero en la representación y en los valores implícitos de una y otra es preciso señalar diferencias significativas.

Mientras que la epopeya cantaba los kléa andrôn, gloria ya realizada en los actos atribuidos a los héroes, el ensalzamiento de la decisión de morir por la ciudad, que se celebra en la oración fúnebre ateniense, no deja lugar al relato de ningún tipo de hechos individuales. El carácter colectivo e igualitario del discurso fúnebre, prescindiendo de toda consideración a la calidad de la vida de los ciudadanos muertos elogiados, los convierte así a todos en merecedores por igual de la misma porción de alabanza. 
La vida del ciudadano no cuenta. Lo realmente importante es la vida de la ciudad. A los que mueren por ella la oración fúnebre les promete participar de

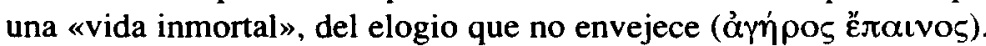

El discurso fúnebre, por un lado, valoriza la memoria ( $\mu \vee \eta j \eta \eta)$ siempre inmortal, y, por otro lado, deprecia la vida de los ciudadanos, y con ella el cuerpo que, así como en la épica se convertía en espectáculo, en los funerales cívicos atenienses se escamotea sistemáticamente.

Como concluye N. LORAuX, se da, con relación a los funerales épicos, el cambio esencial que sustituye el bello muerto por la bella muerte: no se ensalza al individuo ejemplar sino un modelo formal de conducta cívica; no se expone lo bello como un atributo del cuerpo sino como una cualidad del acto de morir por la ciudad. ${ }^{16}$

Como nos cuenta Tucídides (II.34,2), lo que Atenas expone de los muertos son los huesos, 'muertos ya abstractos' porque «están ya privados de todo lo que constituía su apariencia física, de todo lo que permitía identificarlos» ${ }^{17}$. Porque esto es lo que se lleva a cabo fundamentalmente en los funerales públicos atenienses: un proceso de abstracción en el que desaparecen los muertos mismos en aras de la idealidad-ciudad. ${ }^{18}$

Atenas parece ocupar en la oración fúnebre el lugar que en la epopeya ocupa Aquiles: es única ( $\mu$ óvๆ), detenta el primer rango, es objeto de admiración universal y modelo a seguir ( $\pi \alpha \rho \alpha ́ \delta \varepsilon เ \gamma \mu \alpha$ ) para todos. Morir por esta ciudad es vivir en la gloria que pervive en el tiempo y se extiende en el espacio como ninguna otra ${ }^{19}$.

${ }^{16}$ LORAUX, NiCOLE, «Mourir devant Troie, tomber pour Athènes, p. 34.

17 Ibid., p. 35.

${ }^{18}$ Este imperativo ideológico explica la inversión realizada en el orden de las operaciones del ritual funerario de los ciudadanos atenienses, en el que, a diferencia del funeral épico en donde la próthesis-espectáculo precedía a la cremación, las familias asistían a una próthesis sin espectáculo y sin individualización porque la quema de los cadáveres tenía lugar previamente en el campo de batalla. Ibid., p. 35 .

19 Ahora bien, el elogio fúnebre de Pericles no permite concluir, como hace LorauX, N., que: «Si la ciudad ocupa el lugar de Aquiles, lo ocupa de manera edificante: la oración fúnebre es una lección de moral (cívica, hoplítica), lo que no era la epopeya. Se acaba por lo tanto con esta hybris que constituía al héroe homérico en toda su ambigüedad. En los epitaphioi, la desmesura está enfrente, del lado de los adversarios. Toda justicia se ha refugiado en Atenas.» Según esta autora se produce «la ocultación, sistemática en la oración fúnebre, de esta potencia (kratos) a la que la epopeya acordaba un amplio espacio en la definición que daba del guerrero: kratos ejercido, dentro de la ciudad, por el pueblo - en los epitaphioi, la democracia no es el poder del demos, sino la patria de la areté-, kratos de la ciudad imperialista, rechazado y transformado en el reconocimiento del valor de Atenas, al final de un concurso de excelencia: en la oración fúnebre, la potencia no tiene derecho de ciudadanía” Ibid., p. 39. En contra de esto está el hecho que en la oración fúnebre Pericles utiliza el término areté sólo dos veces (Il.36,1 y 40,4), pero no la considera condición 
Cuando Pericles en el elogio fúnebre se refiere a la democracia, destaca no el igualitarismo sino la libertad, la falta de trabas para que cada uno, según sus méritos y condiciones, participe en el gobierno y preste servicio a la ciudad (II.37,1). Es significativo que en estas líneas que hablan de la democracia se destaque la libertad positiva de cada ciudadano a prestar servicio a su ciudad según sus capacidades (II.37,1 y 2), y se omita toda referencia a lo azaroso y obligatorio de los cargos por sorteo así como a su retribución. La explicación de esto radica, a mi modo de ver, en el hecho de que la ideología de la ciudad, de la que es portavoz Pericles, concibe implícitamente la polis según la metáfora del organismo biológico. Las partes integrantes de un organismo desempeñan distintas funciones según sus propias cualidades y no pueden distribuirse por sorteo. Esta metáfora del organismo acentúa el acoplamiento del individuo en la comunidad. Más adelante, en el mismo elogio fúnebre, tras aludir a la compatibilidad de la atención a los asuntos particulares con la dedicación a los públicos, afirma Pericles: «Somos, en efecto, los únicos que a quien no toma parte en es-

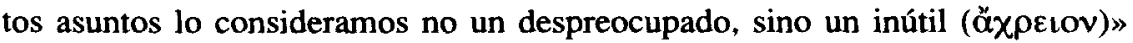
$(40,2)$. Es decir, no estar integrado activamente en el organismo que es la comunidad política equivale a la anulación, a convertirse en una hoja desprendida del árbol que le da la vida. El buen ciudadano, por el contrario, debe de prestar a la ciudad una dedicación y entrega de amante: «Debeis contemplar, en cambio, el poder ( $\delta \dot{v} v \alpha \mu \nu$ ) de la ciudad en la realidad de cada día y convertiros en sus amantes ( $(\xi \rho \alpha \sigma \tau \hat{\alpha} \varsigma) »(43,1)$, les dice Pericles a los atenienses.

Por una siniestra ecuación Pericles asocia la felicidad al riesgo bélico que puede llevar a la muerte, al dirigirse a sus conciudadanos con estas palabras: «estimando que la felicidad se basa en la libertad y la libertad en el coraje, no miréis con inquietud los peligros de la guerra». (II.43,4). Así la mayor entrega a la ciudad, a la vez que realización del ideal de libertad, es la del que da su vi-

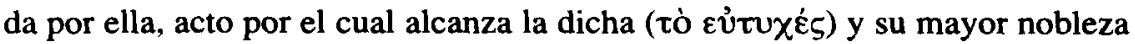

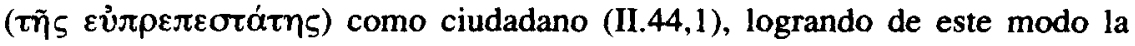
participación en la inmortalidad del renombre de la ciudad, pues «el amor a la

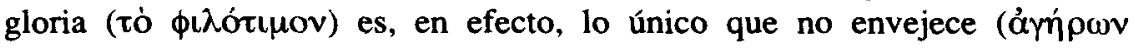

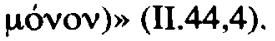

En su último discurso el estadista insiste en que «hay que dejar, pues, de dolerse de los sufrimientos individuales y ocuparse de la salvación de la co-

suficiente para ganarse el anhelado recuerdo eterno y la admiración de generaciones futuras, para lo cual, como proclama el gobernante ante los atenienses, se requiere «haber obligado a todo el mar y toda la Tierra a ser accesibles a nuestra audacia». (II 41,4$)$. Pericles concede un puesto principal, en su discurso fúnebre, a este belicoso valor supremo que es la gloria de la polis (en la que se insiste con distintos términos más de media docena de veces). 
munidad» (II.61,4). El carácter ideal de la comunidad a la que se refiere se manifiesta con claridad en sus propias palabras cuando, refiriéndose al poder que

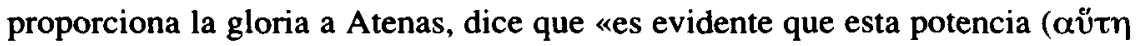

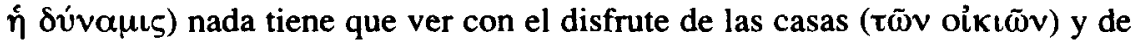
las tierras, a cuya privación dais una gran importancia» $(62,3)$.

Queda claro así el procedimiento de subordinación de la vida y de los bienes del individuo a la idea de ciudad, así como el papel que el anhelo de gloria desempeña en dicho proceso. El deseo de inmortalidad, de gloria, del individuo es un resorte fundamental en la identificación con la idea-ciudad, ya que sólo como partícipe de la gloria imperecedera de ésta puede satisfacer el ciudadano esa ambición. $Y$ es este deseo de una fama eterna y universal lo que empuja a un esfuerzo ilimitado por 'tener cada vez más'. Este universalismo de dominación es totalmente incompatible con la moderación. Por eso la táctica aconsejada por Pericles de «no extender el imperio durante la guerra» (I.144,1; II.65,7), (que constituye el argumento fuerte, si no el único, de los que ven en este estadista el paradigma de la prudencia y del buen juicio), entraba frontalmente en contradicción con los impulsos que la ideología de la ciudad fomentaba y que no encontraban ningún tipo de instancia superior, religiosa o laica, que los limitara.

La expedición a Sicilia no es una empresa anómala, resultado de mentes enloquecidas, sino que está impulsada por el coraje y el amor a la gloria imperecedera que Pericles ha ensalzado como propios de Atenas. Así como Pericles instaba a los atenienses a convertirse en los amantes (દ̉paơó́ৎ) de su ciudad (II.43,1), Tucídides habla del eros de los atenienses por la expedición de Sicilia (VI.24,3 ${ }^{20}$. De acuerdo con Leo STRAuss, «se podría decir que, según Pericles mismo, <Atenas en Sicilia> es más grande que la Atenas de Pericles: supera a cualquier otro «monumento imperecedero de los males» (II.41,4) que Atenas ha podido dejar detrás de ella. El eros del ateniense por Sicilia es la cima de su amor por la ciudad, y este eros es consagración total a su ciudad, voluntad de sacrificarse, de olvidar todo bien privado en favor de la ciudad, una voluntad que encuentra una expresión apropiada y por lo tanto no desprovista de ambiguiedad en lo que dice Pericles en la oración fúnebre a proposito de los parientes ancianos, de las viudas y de los huérfanos de los soldados caídos. O también, como lo indica Alcibiades, sólo la gloria en la muerte produce la armonía perfecta entre lo privado y lo público (VI.16,5). Si el eros más gran-

${ }^{20}$ STRAuss, LEO, op. cit., p. 284, observa, en una nota, que «Esta es la única vez en que Tuć́dides mismo utiliza la palabra eros. Uno solo de sus personajes hace uso de ella: Diodoto (III.45,5). Cuando interviene contra la expedición de Sicilia, Nicias censura a los dyserotes tôn apontôn $(\mathrm{VI}, 13,1)$. 
de es el que siente por la ciudad y si la ciudad alcanza su apogeo por un eros semejante a éste de Atenas por Sicilia, eros es necesariamente trágico o, como Platón parece sugerirlo, la ciudad es la tragedia par excellence». ${ }^{21}$

El discurso de Tucídides no debe de confundirse con el discurso de Pericles. Tucídides no se identifica con 'Atenas' sin reservas. El modo como está estructurado su relato histórico es ilustrativo en este sentido.

En el Libro I, dedicado a la exposición de las causas de la guerra, inmediatamente después del debate de Esparta en el que los atenienses habían afirmado que Atenas, aún pudiendo ejercer el derecho natural del más fuerte, era moderada y respetuosa en el ejercicio de su hegemonía, Tucídides coloca la 'Pentecontecia' en la que niega abierta y explícitamente estas afirmaciones al referir el proceso de conversión de Atenas en imperio (proceso que es considerado la verdadera causa de la guerra) ${ }^{22}$.

El Libro I termina con el primer discurso de Pericles, en el que insta a los atenienses a la guerra y les presenta la clave de su estrategia: abandonar las tierras y las casas y concentrarse todos dentro de los muros de la ciudad, evitando el enfrentamiento en campo abierto con los peloponesios y manteniendo el dominio del mar.

La narración del Libro II, tras una observación acerca de la ordenación cronológica en veranos e inviernos del relato, comienza con la entrada de los

21 En nota remite a Leyes 817 b. Ibid., pp. 284-85.

22 El historiador levanta acta del menoscabo de derechos y de relaciones de igualdad con los aliados que conllevó la conversión de la hegemonía ateniense en imperio, así como de las intervenciones militares de Atenas por conquistar más posesiones. Al relatar el comportamiento de Atenas en este periodo (que uha sido descuidado por todos mis predecesores» 1.97,2), Tucídides rebate punto por punto la imagen que los atenienses dan de su actitud. El historiador nos cuenta que:

- Atenas deja de tratar como autónomos a sus aliados y de permitirles la participación común en sus decisiones $(1.97,1 ; 1.99,2)$. Esto es, una negación evidente de las relaciones de igualdad.

- Atenas dirige acciones políticas y militares que le enfrentan, no sólo a los bárbaros, sino tambiến a sus aliados $(1.97,1)$.

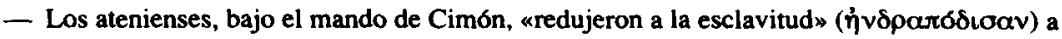
los pueblos de Eyón y Esciro.

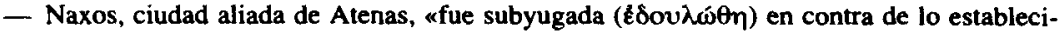
do, pero después las demás, una tras otra, sufrieron la misma suerte». (1.98,4). Es decir, Atenas viola los acuerdos legales vigentes según los cuales los miembros de la Liga eran considerados estados autónomos.

Es muy significativo que Tucídides destaque estos hechos justo después de las afirmaciones de los atenienses a las que desmienten. $Y$ lo es también que la primera y única aparición de Pericles, en la narración que da cuenta del apogeo de Atenas, sea como jefe militar en campaña de conquista. (1.111,2). 
tebanos en Platea y la posterior invasión del Atica, que constituye el verdadero comienzo de la guerra del Peloponeso. La figura de Pericles, que murió a los dos años y medio del inicio del conflicto, domina este libro que abarca los tres primeros años de la guerra. Los hechos provocados por las ideas expresadas en el plan de Pericles en el discurso que ponía fin al libro anterior cobran ahora protagonismo.

En este Libro II Tucídides nos muestra los efectos de la política pericleana de concentración de los atenienses en el interior de la ciudad. Tras poner de manifiesto que «el traslado, empero, lo realizaban a disgusto, debido a que la mayoría tenía desde siempre la costumbre de vivir en el campo» (II.14,2), introduce una disgresión sobre la organización política del Atica encaminada a destacar la antiguiedad y arraigo de este modo de vida que ahora se veían obligados a abandonar ${ }^{23}$.

Que el coste que supuso el abandono de casas y tierras no era sólo de orden material sino que conllevaba una profunda carga cultural, religiosa y afectiva es algo que a Tucídides le interesa dejar patente. Por ello insiste en su narración en que: «Así, pues, los atenienses durante mucho tiempo compartieron la vida en el campo en un régimen autonómico, y, una vez que se unificaron políticamente, aún así, la mayor parte de ellos, tanto antiguamente como después hasta nuestra guerra, siguieron viviendo en los campos con toda su familia debido a la fuerza de la costumbre ( $\delta \iota \alpha$ tò $\mathbf{z} \theta \theta_{\zeta}$ ); por esto no procedieron de buen grado a los traslados, máxime cuando hacía poco que habían vuelto a poner en marcha sus casas después de las Guerras Médicas. Estaban apesadumbrados y soportaban mal el dejar sus casas y sus templos, que siempre habían sido suyos como una herencia de sus padres desde los tiempos de su antigua organización política, teniendo que cambiar de modo de vida y debiendo abandonar cada uno nada menos que su propia ciudad

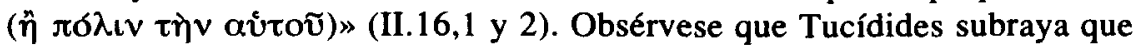
lo que se sacrifica en aras del ideal-ciudad no es otra cosa que la ciudad propia y vivida.

A los costes de la renuncia a su ancestral modo de vida se suman los derivados de la falta de espacio en el recinto de la ciudad para acoger a toda esta población proveniente del campo. En la descripción de Tucídides Atenas apa-

${ }^{23}$ Así nos cuenta que: «Esta costumbre se había dado desde muy antiguo entre los atenienses más que entre otros pueblos. En efecto, desde los tiempos de Cécrope y de los primeros reyes hasta la época de Teseo, los habitantes del Atica vivieron siempre repartidos en pequeñas ciudades, cada uno con sus pritaneos y sus magistrados» $(15,1)$ y, a pesar de la unificación política del Atica en la ciudad de Atenas, que se le atribufa a Teseo, «siguieron ocupando sus tierras separadamente igual que antes» $(15,2)$. 
rece convertida en una especie campo de refugiados en el que reina el hacinamiento ${ }^{24}$.

La narración de Tucídides prosigue refiriéndonos el avance de los peloponesios hasta Acarnas, «el territorio más extenso de los llamados demos del Atican, cuya devastación fue el espectáculo que durante mucho tiempo se ofreció ante los ojos de los atenienses, provocando la irritación popular contra $\mathrm{Pe}$ ricles, al que consideraban «responsable de todos sus sufrimientos». Este mantenía su estrategia de no salir a dar batalla a campo abierto y «no los convocaba ni a la asamblea ni a ninguna reunión, para evitar que se equivocaran al reunirse con más cólera ( $\delta \rho \gamma \tilde{)})$ que juicio ( $\gamma w \omega ́ \mu \eta) »$ (II.22.1). Después de asolar Acarnas, viendo que los atenienses no salían a prestarles batalla, los peloponesios devastaron algunos otros demos del Atica, antes de retirarse cuando se les acabaron los víveres. Tras relatar diversas empresas de los atenienses durante el verano, y la expedición de la flota corintia contra Acarnania y Cefalenia, el relato de Tucídides nos ofrece la descripción de los funerales de los muertos en este primer año de guerra y el elogio fúnebre de Pericles.

Es muy significativo que estos funerales y esta loa, que insiste en la gloria venidera como valor supremo de ese ente abstracto en el que se convierte la ciudad así ensalzada, estén precedidos en la ordenación narrativa tucidideana por la exposición de todos los efectos destructivos que los atenienses tuvieron que sufrir en sus modos de vida, casas y tierras. El resplandor de la gloria venidera de Atenas, celebrada por Pericles, parece de hecho requerir el fuego devorador de los modos de vida de la mayoría de los atenienses y de «nada menos que su propia ciudad» (II.16,2).

Pero es más relevante aún que al discurso fúnebre de Pericles le siga inmediatamente el relato de la peste que asolo a Atenas ${ }^{25}$, en el segundo año de

24 Así, se detiene el historiador en contamos que: «cuando llegaron a la capital, eran pocos los que tenían su casa o encontraban alojamiento en casa de amigos o parientes; la mayoría se instalaron en los sitios deshabitados de la ciudad y en todos los templos y santuarios de los héroes, salvo la Acropolis, el Eleusinio y otros lugares bien cerrados. Incluso el llamado Pelárgico situado al pie de la Acrópolis, sobre el que pesaba una maldición que prohibía habitarlo, del mismo modo que también lo impedía un final de verso de un oráculo pítico que decía El Pelárgico está mejor desocupado, a pesar de esto, debido a la necesidad del momento fue totalmente utilizado como alojamiento" (II.17,1-2). Y continúa relatando que «también se instalaron muchos en las torres de las murallas, y en otros sitios, como podía cada uno. La ciudad, en efecto, no tuvo cabida para todos los que concurrieron; luego, repartiéndose el sitio, ocuparon los Muros Largos y la mayor parte del Pireom. (II.17,3-4).

25 STRAUSS, LEO, le concede a este hecho una importancia capital: «la oración fúnebre es seguida de la peste y el diálogo con los melios es seguido por el desastre de Sicilia. He aquí to que podría parecer la enseñanza más general de Tucídides, comunicada silenciosamente, siendo este silencio requerido por el carácter severo de su piedad». (op. cit. p. 196). 
la guerra, coincidiendo con la segunda invasión y devastación del Atica por los peloponesios. El contraste es elocuente. En el discurso de Pericles se escamotea el sufrimiento físico de la guerra, y, a pesar de la condición fúnebre del elogio se evita el empleo de palabras como «morir», "cadáver» o "muerte». Esta última sólo la encontramos una vez en todo el discurso fúnebre, en la expresión

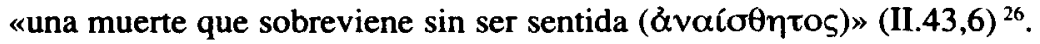

Por el contrario, la minuciosa y extensa descripción de la peste, además de ser reiterativa en el uso de las palabras «la muerte», «los muertos», «morir» y «cadáveres», nos da cuenta pormenorizada de todos los sufrimientos acarreados por esta enfermedad que «atacó a cada persona con más virulencia de la que puede soportar la naturaleza humana» (II.50,1; cf. II.49,2-50). Los muertos y las muertes no repentinas, sino como desenlace de un largo proceso (más de 769 días) de verdadera tortura (II.49,6), ocupan el centro de la escena. Tucídides no deja de llamar la atención acerca de la contribución de la estrategia de Pericles de concentración dentro de la ciudad al agravamiento de este cuadro de horrores ${ }^{27}$.

Después de exponer los efectos en el aumento de la inmoralidad que la epidemia acarré (II.52,4 y 53), Tucídides, a modo de balance, escribe: «tal era el agobio de la desgracia en que se veían sumidos los atenienses; la población moría dentro de las murallas y el país era devastado fuera». (II.54,1).

A los extensos pasajes dedicados a la peste (del II.47,3 al 55) les siguen unos breves párrafos que dan cuenta de la magnitud del saqueo del Atica por los peloponesios (en «la invasión en que permanecieron más tiempo y asolaron todo el territorio» II.57,2), así como de la expedición naval no del todo fructífera que los atenienses dirigieron contra el Peloponeso y de la expedición frustrada contra Calcídica y Potidea, que no obtuvo más saldo que la propagación de la epidemia entre los soldados atenienses que allí se encontraban asediando esas plazas, y la retirada forzosa de las naves a Atenas, con el saldo de 1.050 de sus 4.000 hoplitas muertos por causa de la enfermedad (II.58,2 y 3 ).

26 Observación debida a STRAuSS, Leo, quien comenta: «Por esto es por lo que cuando Pericles hace alusión al acontecimiento supremo de la muerte, no lo hace durar más que un momento muy breve», y en nota remite a «II.42,4. Cf. también 43,2, principio, donde parece negar que la muerte sea propia de cada uno a la vez que afirma que <la alabanza eternamente memorable [no 'inmortal'] pertenece como propia a cada uno». op. cit., p. 247.

27 «En medio de sus penalidades les supuso un mayor agobio la aglomeración ocasionada por el traslado a la ciudad de las gentes del campo, y quienes más la padecieron fueron los refugiados. En efecto, como no había casas disponibles y habitaban en barracas sofocantes debido a la época del año, la mortandaz se produća en una situación de completo desorden; cuerpos de moribundos yacían unos sobre otros, y personas medio muertas se arrastraban por las calles y alrededor de todas las fuentes movidos por su deseo de agua. Los santuarios en los que se habran instalado estaban llenos de cadáveres, pues morian allí mismo» (II.52,1-4). 
Todas estas calamidades provocadas por la enfermedad y la guerra (II.57,1), suscitaron una vez más entre los atenienses el descontento contra Pericles. Le acusaban «de haberles persuadido a hacer la guerra y de ser el responsable de que hubieran caído en aquellas desgracias, y anhelaban llegar a un acuerdo con los lacedemonios; les enviaron incluso unos embajadores, pero no consiguieron nada». (II.59,2).

Con motivo de la primera reacción belicosa de los atenienses ante la primera invasión del Atica, Pericles había optado por no reunir al pueblo, que veía presa de cólera. Ahora, que buscan la paz, el estadista les convoca a asamblea para enardecerles. Es en este punto de la narración donde Tucídides inserta el tercer y último discurso de Pericles. La disonancia del logos con el ergon, el contraste de la arenga con lo que hasta ahora nos estaba describiendo el historiador, es difícilmente eludible en una lectura sin prejuicios. Después de todo el expresivo cuadro de pérdidas, horror y muerte, que Tucídides se ha detenido en exponer, nos encontramos con este discurso de Pericles que empieza denigrando la actitud de anteponer la preocupación del bienestar inmediato y particular al interés de la ciudad (II.60), pretendiendo de este modo relegar retóricamente a la categoría de asunto particular y privado un cúmulo de calamidades, destrucción y sufrimiento que por su intensidad y extensión constituía una cuestión pública y política, si no el problema público número uno de la comunidad.

Oigamos a Pericles: «Esperaba las manifestaciones de vuestro enfado contra mí, pues conozco sus causas, y por esto he convocado la asamblea, para refrescar vuestra memoria y recriminaros si es que sin ninguna razon os enojais conmigo o cedéis ante las desgracias. Tengo para mí, en efecto, que una ciudad que progrese colectivamente resulta más útil a los particulares que otra que tenga prosperidad en cada uno de sus ciudadanos, pero que se esté arruinando como Estado. Porque un hombre cuyos asuntos particulares van bien, si su patria es destruida, él igualmente se va a la ruina con ella, mientras que aquél que es desafortunado en una ciudad afortunada se salva mucho más fácilmente. Siendo así, pues, que una ciudad puede soportar las desgracias privadas, mientras que los ciudadanos particularmente son incapaces de soportar los de aquélla, ¿cómo no va a ser misión de todos defenderla y no hacer lo que vosotros ahora? Abatidos por las desventuras de vuestras casas, os despreocupais de la salvación de la comunidad.» (II.60,1-5).

Si tenemos presente el relato de las calamidades que asolan la ciudad, como la ordenación de la narración al hacerlo preceder a este discurso así lo pretende, no podemos leer estas palabras de Pericles sin que quede patente, además de su pretensión de minimizar el desastre, la conversión de la ciudad en idea, pues no puede ser otra cosa que la idea de ciudad la que puede soportar 
tal magnitud de sufrimientos («la población moría dentro de las murallas y el país era devastado fuera») y vivir gloriosamente a costa de la muerte del conjunto de la población que la compone. La comunidad cuya salvación se postula instando a seguir la guerra en esta creciente situación calamitosa queda claro que no es la colectividad de los ciudadanos como seres vivos.

Así Pericles prosigue su discurso aludiendo a su carácter de patriota e instando al amor a la patria (II.60,5 y 6); después reconoce el carácter tiránico del imperio ateniense al que "ya no es posible renunciar»; y, finalmente, se extiende en las loas a ese bien supremo que es la gloria eternamente memorable que procura el imperio. Pericles reconoce que las calamidades presentes, provocadas por la epidemia y el enemigo, son el pasto con el que se alimenta esta fama futura de la ciudad. En este sentido afirma que «hay que soportar los males enviados por los dioses con resignación y los que proceden de los enemigos con valor; tal era, en efecto, la costumbre de esta ciudad en el pasado, y ahora es preciso que no se interrumpa en vosotros. Daos cuenta que ella goza

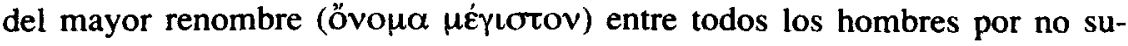
cumbir a las desgracias y por haber gastado en la guerra más vidas y esfuerzos que ninguna otra; pensad también que ella posee la mayor potencia conseguida hasta nuestros días, cuya memoria ( $\mu v \eta \dot{\mu} \eta \eta)$, aunque ahora llegáramos a ceder un poco (pues todo ha nacido para disminuir) perdurará para siempre en las generaciones futuras» (II.64,2 y 3 ).

Tucídides hace seguir a este último discurso de Pericles un extenso pasaje en el que expresa directamente su valoración del estadista. Exalta los méritos de este personaje a cuyo gobierno de la ciudad en tiempos de paz atribuye

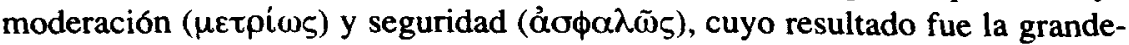
za de Atenas; "y una vez que la guerra estallo, también en aquellas circunstancias quedó claro que había previsto su potencia». (II.65,5).

Conviene advertir que en ninguno de los discursos de Pericles se alude a la moderación como un valor. Tucídides, en su juicio directo sobre el personaje, sólo le atribuye la virtud de la moderación en época de paz; en tiempo de guerra no aparece mencionado tal valor como mérito del gobernante, sino «la clarividencia ( $\pi \rho o ́ v o l \alpha)$ de sus previsiones respecto a la guerra» (II.65,6). Prueba de esta clarividencia era que «sostenía, en efecto, que los atenienses vencerían si permanecían tranquilos y se cuidaban de su flota sin tratar de acrecentar su imperio durante la guerra y sin poner la ciudad en peligro». (II.65,7).

En este punto tenemos que hacer algunas observaciones. En primer lugar es preciso advertir que Tucídides reconoce que la estrategia de Pericles podía llevar a la victoria de la guerra, pero deja claro los gravísimos costes de esta estrategia, que podían tornar esta victoria en un ejemplo de derrota. Es decir, valorar la clarividencia en el desarrollo de la guerra, una vez metidos en ella, no 
equivale a ensalzar o aprobar la opción por la guerra. En esto el silencio de Tucídides es revelador. De hecho, el historiador, al comienzo de su juicio sobre Pericles, hace referencia al efecto persuasivo sobre los atenienses del último discurso de su gobernante en estos términos: «no enviaron más embajadas a los lacedemonios y se entregaron a la guerra con más ardor; pero en privado, seguían con el dolor de sus sufrimientos: el pueblo, porque contando inicialmente con menos recursos se veía privado incluso de éstos, y los poderosos, porque habían perdido las hermosas posesiones que tenían en el campo con sus construcciones y costosas instalaciones; pero lo más doloroso era que tenían la guerra en lugar de la paz». (II.65,2-3).

En segundo lugar, no puede pasar por moderada una política que acarrea y asume unas calamidades de la magnitud que Tucídides nos ha mostrado, sólo por el hecho de ser comedida tácticamente en su ambición de expansión geográfica. Y menos aún cuando los valores que se enarbolan para mantenerse en guerra, y no ceder ante tales desgracias, aún conscientes de su agravamiento, son valores, como hemos visto, incompatibles con la moderación. (Tucídides sin embargo sí elogia la moderación espartana).

En tercer lugar, en su valoración del estadista Tucídides no afirma que Pericles hubiese condenado la expedición a Sicilia. Acometer la empresa de la expedición a Sicilia no se presenta como ningún despropósito, fruto de un error en la apreciación de las fuerzas. Lo que pone en evidencia el fracaso de esta expedición, según el historiador, es más bien la ausencia de un gobernante con independencia y autoridad como Pericles (II.65,8). Tucídides no contrapone la política de Pericles a la expedición de Sicilia, «cuyo fracaso no se debió tanto a un error de cálculo respecto a las fuerzas contra las que se dirigía el ataque como al hecho de que aquellos que habían enviado la expedición no adoptaron luego las medidas que convenían al cuerpo expedicionario, sino que, a causa de sus desavenencias personales respecto a la jefatura del pueblo, debilitaron las fuerzas del ejército $y$, por primera vez, el gobierno de la ciudad se vio turbado por discusiones internas». (II.65,11-12). Es decir, Tucídides no dice que la política de Pericles fuese incompatible con la expedición de Sicilia sino todo lo contrario; para una exitosa expedición de Sicilia se requería un Pericles.

Tucídides no elogia a Pericles, ni le contrapone a sus sucesores, por su moderación, sino por su independencia e insobornable dedicación al bien común (II.65,8), aún a costa de tener que oponerse a la multitud y ganarse su odio (II.65,8 y 9). Pero el bien común para Pericles, en lo que se refiere a la ciudad, es la gloria, la nobleza, que, como hemos visto, no se puede reducir a lo agradable y al bienestar, sino que es muy superior a ellos, e incluso a la justicia misma (II.63,2). 
La idea-ciudad limita y orienta el campo de aplicación del juicio y se sitúa a la vez fuera de su alcance. Es más, la salvaguarda de la idea de ciudad como valor supremo obliga a Pericles a actuar en contra de la gnome, y excitar pasiones anuladoras de toda capacidad de razonar como la ambición y el temor. (cf. II.65,9). Así lo que se expone dramáticamente en la narración de Tucídides son las fuerzas irracionales y destructivas que puede albergar esta manera de considerar el 'bien común' ${ }^{28}$.

Tucídides ensalza, por una parte, la dedicación de Pericles al bien público y, por otra, muestra en toda su crudeza, no sólo en esta parte sino en el conjunto de su Historia, los costes de este ideal de ciudad. Esta actitud del historiador más que de contradictoria se puede calificar de trágica, pues, aunque sensible y consciente del sufrimiento que esta idea de ciudad soberana acarrea, no puede expresar una conclusión condenatoria contra ella, ni trascender su marco.

Sin embargo, por encima del silencio de Tucídides se impone la elocuencia de su texto, en el que la ciudad ocupa el lugar de Aquiles, pero no «de manera edificante». La desmesura y la violencia erradicadas en las relaciones entre ciudadanos reaparecen, ligadas al valor supremo de la gloria de la polis, en el plano de la comunidad como entidad, incitando así a la conquista y destrucción de otras comunidades. El agravante, con relación al poder del héroe guerrero, es que en el caso de la ciudad, a parte del mayor alcance de su capacidad de destrucción, no hay ninguna instancia superior a ella que la refrene. Por encima del ideal-ciudad, que Pericles asume y predica, no hay ningún valor. Esta es una de las cuestiones centrales que la Historia de la Guerra del Peloponeso de Tucídides plantea a los lectores de hoy.

2. Strauss, LeO, advierte el fomento de las ambiciones personales que esta manera de considerar el bien común acarrea, pues " $i S e$ puede alentar a la ciudad, como lo hace Pericles, a desear "tener más» que las otras ciudades sin alentar a la larga el deseo del individuo a «tener más» que su conciudadano?», op. cit. p. 246. 